\title{
Targeting Tumor Hypoxia in Radiotherapy: A Brief Review of Historical Background and Recent Progress
}

\author{
Mutian Zhang ${ }^{1 *}$, Zhengyuan Zhou ${ }^{2}$, Zhihong Zhao ${ }^{3}$ and Jered Garrison ${ }^{2}$ \\ ${ }^{1}$ Department of Radiation Oncology, University of Nebraska Medical Center, Omaha, NE 68198, USA; ${ }^{2}$ Department of Pharmaceutical \\ Sciences, University of Nebraska Medical Center, Omaha, NE 68198, USA, ${ }^{3}$ Munroe-Meyer Institute, University of Nebraska Medical \\ Center, Omaha, NE 68198, USA
}

\begin{abstract}
Tumor hypoxia is a physiologic barrier to radiotherapy and anti-tumor drug delivery. Numerous efforts have been made to overcome this barrier and to improve therapeutic outcomes. Strategies for targeting tumor hypoxia have included chemical radiosensitizers and hyperthermia, followed by combined synergic therapeutic modalities. Clinical hypoxia measurements and the development of molecular imaging agents prompted trials on dose escalation in external beam radiotherapy, which takes advantage of contemporary sophisticated radiation dose delivery techniques. Increases in our understanding of hypoxia-induced biological pathways have led to the investigation of various hypoxia targeting drugs. Radiolabeled hypoxia targeting drugs deliver radionuclides into hypoxic tumor cells and achieve highly localized cell death. In this manuscript, we briefly review the methods of targeting tumor hypoxia in radiotherapy. These include image guided dose escalation in external beam radiotherapy, radiosensitizers, and radiolabeled agents targeting hypoxia pathways and the receptors on hypoxic tumor cells. Our current understanding of tumor hypoxia is the culmination of the collective efforts of generations of researchers. New frontiers are continuing to expand, as new discoveries are being made on both the macroscopic and molecular levels.
\end{abstract}

\section{Introduction}

Tumor hypoxia is a distinct characteristic of solid tumors and results from an imbalance between the cellular oxygen consumption rate and tumor oxygen supply.[1] Primarily, available oxygen is consumed within 70 to $150 \mu \mathrm{m}$ of tumor vasculature by rapidly proliferating tumor cells[2]; thus, the remaining tumor cells outside this range fall in a microenvironment of low oxygen. Hypoxia

Keywords: Hyperthermia; Monoclonal antibody; Radiosensitizer; Radiotherapy; Receptor-targeted radiopharmaceutical; Simultaneous dose escalation; Tumor hypoxia. Abbreviations: ${ }^{18} \mathrm{~F}$-MISO, ${ }^{18} \mathrm{~F}$-fluoromisonidazole; CAIX, carbonic anhydrase 9; ccRCC, clear-cell renal cell carcinoma; FDG, fluorodeoxyglucose; HIF-1 $\alpha$, hypoxiainducible factor 1-alpha; IMRT, intensity-modulated radiation therapy; MTH, mild temperature hyperthermia; NSCLC, non-small cell lung cancer; PET, positron emission tomography; $\mathrm{pO}_{2}$, partial pressure of oxygen; VEGF, vascular endothelial growth factor; VHL, von Hippel-Lindau.

Received: 12 September 2015; Revised: 10 December 2015; Accepted: 31 December 2015

DOI: 10.14218/ERHM.2015.00004

*Correspondence to: Mutian Zhang, Department of Radiation Oncology, University of Nebraska Medical Center, Omaha, NE 68198, USA. Tel: +1-402-552-3844, E-mail: mutianzhang@unmc.edu increases tumor resistance to radiation and is considered a poor prognostic factor in human cancers and is an important reason for the failure of radiation therapy. Accumulating evidence shows that hypoxia is responsible for inducing drug resistance[3] and correlates with increased distant metastases.[4] Therefore, hypoxia and hypoxia-related tumor microenvironments have become major targets for the development of cancer treatment.

Phenomena of tumor hypoxia

Tumor hypoxia can be quantified by the locoregional partial pressure of oxygen $\left(\mathrm{pO}_{2}\right)$. Though the $\mathrm{pO}_{2}$ value is not a precise measure of the severity of tumor hypoxia and its biophysiological consequences, many researchers choose an arbitrary $\mathrm{pO}_{2}$ value of 5 $\mathrm{mmHg}$ as the threshold of tumor hypoxia, and the fraction of tumor cells present in oxygen tension below this threshold is termed the hypoxic fraction.

Extensive work has been performed on refining the measurements of tumor hypoxia in animal models as well as in human patients. Quantitative measurements of $\mathrm{pO}_{2}$ values can be performed using invasive probes that can provide instantaneous locoregional tumor oxygen tension in vivo.[5,6] Two types of $\mathrm{pO}_{2}$ probes are frequently used to measure hypoxia: polarographic needle electrodes[5] and luminescence-based optical probes.[6] The microscopic distribution of hypoxia can be determined utilizing immunohistochemical staining with endogenous or exogenous hypoxia markers. An example of an endogenous hypoxia marker is carbonic anhydrase 9 (CAIX), a transmembrane protein that is overexpressed in hypoxic cells in a variety of tumors.[7,8] Commonly used exogenous surrogate hypoxia markers are compounds that are bioreducible within hypoxic cells, such as pimonidazole,[9] for which a commercial fluorescent antibody is available to reveal its microscopic distribution within the tumor. Positron emission tomography (PET) and single photon emission computed tomography are used to image exogenous hypoxia markers labeled with radiotracers, such as the widely used ${ }^{18} \mathrm{~F}$-fluoromisonidazole $\left({ }^{18} \mathrm{~F}\right.$ MISO) $[10,11]$ and the clinically validated ${ }^{64} \mathrm{Cu}$-labeled agents [e.g., ${ }^{64} \mathrm{Cu}$-diacetyl-bis $\left(N^{4}\right.$-methylthiosemicarbazonate) $\quad\left({ }^{64} \mathrm{Cu}\right.$-ATSM $\left.)\right]$. [12] Fig. 1 shows the structures and bioreduction mechanisms of ${ }^{18} \mathrm{~F}$-MISO and ${ }^{64} \mathrm{Cu}$-ATSM. Magnetic resonance spectroscopy of surrogate markers such as lactate, a metabolic product of anaerobic glycolysis,[13] or the evaluation of the tumor blood perfusion with dynamic contrast-enhanced magnetic resonance imaging has been used to noninvasively probe tumor hypoxia.[14]

Hypoxia exists in solid tumors at every growth stage. Even in its earliest phase of growth, the tumor in situ may develop intense 


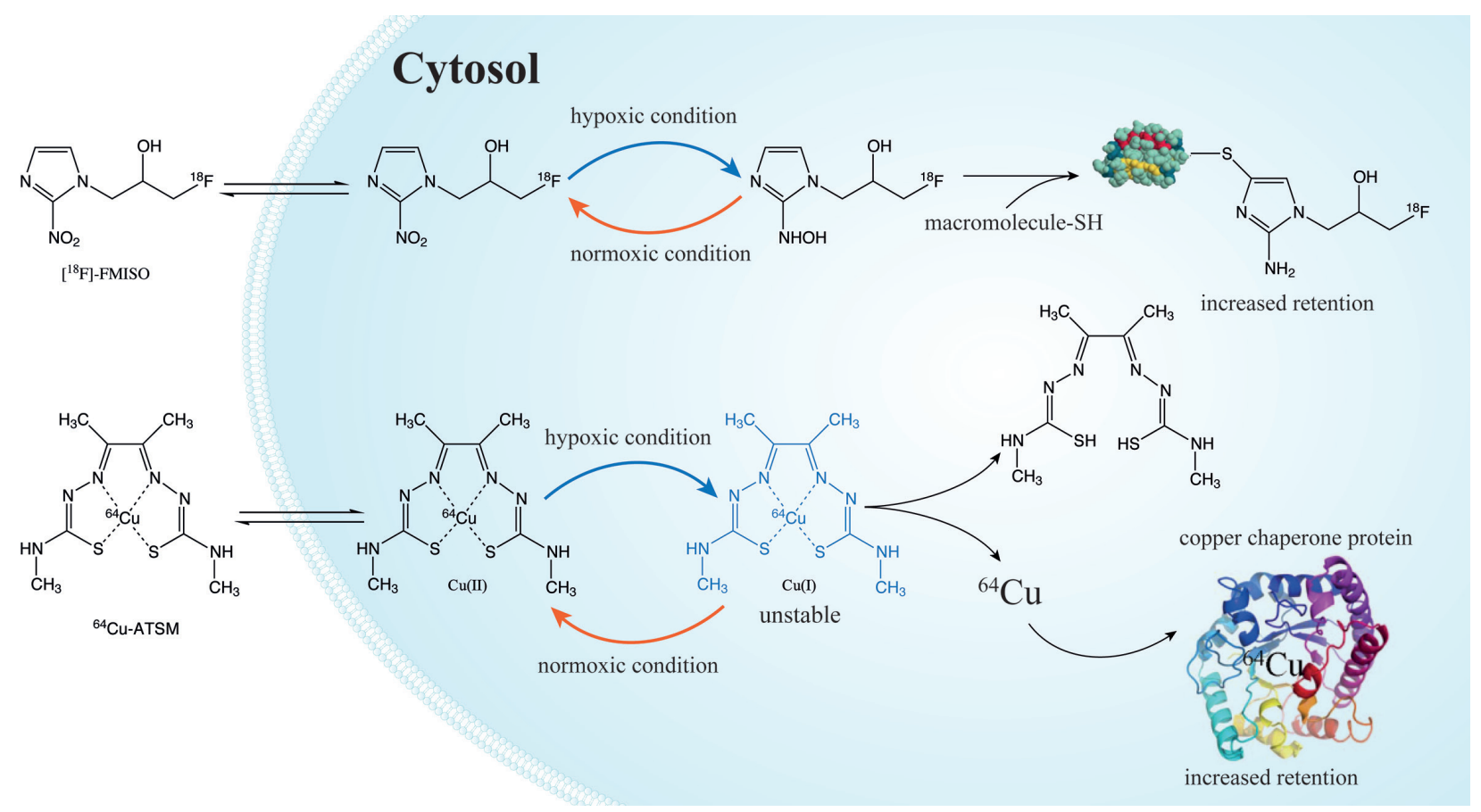

Fig. 1. The molecular structures of ${ }^{18} \mathrm{~F}$-fluoromisonidazole $\left({ }^{18} \mathrm{~F}\right.$-MISO) and ${ }^{64} \mathrm{Cu}$-diacetyl-bis $\left({ }^{4}\right.$-methylthiosemicarbazonate) $\left({ }^{64} \mathrm{Cu}\right.$-ATSM) and their bioreductive mechanisms in hypoxic cells.

hypoxia.[15] Hypoxic tumor cells secrete hypoxia-inducible angiogenic factors, such as vascular endothelial growth factor (VEGF), to trigger the growth of new blood vessels into the tumor, a process termed angiogenesis.[16] As the tumor grows larger, there is an abrupt decline in the hypoxic fraction, indicating the onset of angiogenesis.[15] Although hypoxia could be temporarily alleviated by the formation of new blood vessels, the tumor will soon outgrow its oxygen and nutrition. Vajkoczy et al. observed that the blood vessel density in transplanted C6 gliomas initially increased; but 10 days after implantation, the blood vessel density reached a maximum and did not further increase.[17] Similarly, Nöth et al. reported that during the first few days following GH3 tumor homogenate injection the tumor $\mathrm{pO}_{2}$ levels increased rapidly, then

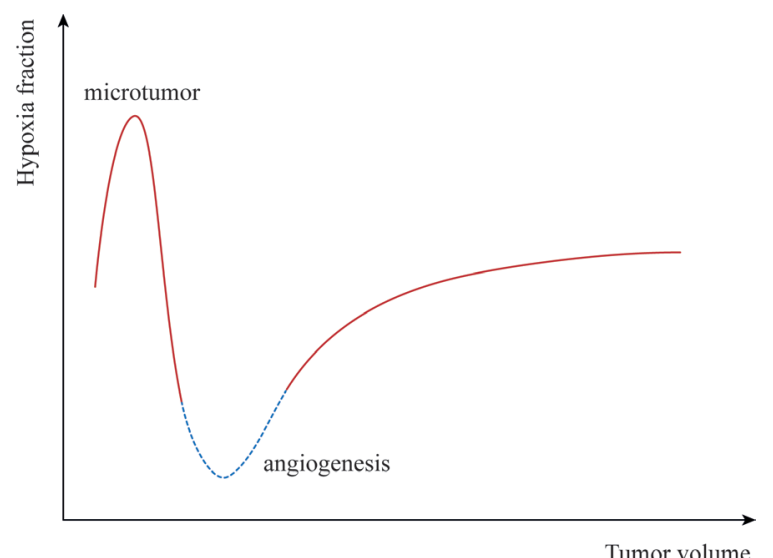

Fig. 2. Development of hypoxia during tumor growth: a conceptual diagram based on currently available data. Before the onset of angiogenesis, the microtumor depends upon diffusion for oxygen and nutrients; following angiogenesis, the hypoxic fraction steadily increases in a clinically detectable tumor. reached a plateau, and then the $\mathrm{pO}_{2}$ level readily decreased.[18] These findings were supplemented by clinical measurements using polarographic needle electrodes in hundreds of patients, which showed increasing tumor hypoxic fraction with increasing tumor volume.[19] The relationship between the extent of tumor hypoxia and tumor volume is conceptually illustrated in Fig. 2.

To date, three types of tumor hypoxia have been identified:[20] the diffusion-limited or "chronic" hypoxia caused by increased diffusion distance; the perfusion-limited or "acute" hypoxia caused by low blood flow; and the recently described macroscopic regional hypoxia caused by extended longitudinal blood flow gradients.[21] Tumor hypoxia is a heterogeneous phenomenon, both spatially and temporally. Spatially, observations on patient biopsies showed that in many tumors the periphery regions had a greater blood supply and, therefore, were well oxygenated, whereas elsewhere, blood vessels were less dense or less functional.[22] Temporally, studies suggest that hypoxia is a dynamic process rather than a static picture. Dewhirst et al. placed an oxygen electrode into R3230AC tumor masses in rats and observed, on occasion, that the $\mathrm{pO}_{2}$ readings fluctuated around the hypoxia threshold a few times per hour. [23] Brurberg et al. found using optical $\mathrm{pO}_{2}$ probes in A-07 human melanoma xenografts that the oxygen tension fluctuated at frequencies less than 0.1 cycle/min.[24] However, the extent to which these preclinical kinetic studies translate to clinical realities is still unknown. This is due to the difficulty in detecting hypoxia fluctuations in human patients and our incomplete knowledge of the underlying kinetics of acute hypoxia.

Biologic and therapeutic consequences of tumor hypoxia

Hypoxia induces a series of biological events in tumors that eventually lead to changes in the tumor microenvironment and resistance to therapy. A signature change in tumor metabolism, historically 
known as the Warburg effect,[25] is due to the reliance of cancer cells on aerobic glycolysis to generate the majority of energy needed for cellular processes. The expression of genes responsible for glycolytic enzymes and glucose transporters is linked to oncogenes that include ras, src, and $c-m y c$.[26,27] As a result, glycolysis is often accompanied by increased glucose uptake, a feature that is exploited in ${ }^{18} \mathrm{~F}$-fluorodeoxyglucose (FDG)-PET.[28]

Hypoxia leads to increases in hypoxia-inducible factor-1 (HIF$1)$, which is the central transcriptional mediator of the cellular response to hypoxia.[29] HIF-1 consists of HIF-1 $\alpha$ and HIF-1 $\beta$ subunits. HIF-1 $\beta$ is a constitutively expressed nuclear protein; whereas the expression of HIF- $1 \alpha$ is regulated at both the translational and posttranslational levels.[30] HIF-1 $\alpha$ expression has been reported to be increased dramatically in conditions where $\mathrm{pO}_{2}$ is less than $40 \mathrm{mmHg}$, and its degradation is retarded at low oxygen concentrations.[31] HIF-1 $\alpha$ is known to induce transcription of more than 60 genes that are expressed at higher levels in cancer, particularly VEGF and enzymes of glucose metabolism. HIF-1 $\alpha$ also induces transcription of genes involved in cell proliferation and survival, which have been shown to correlate with tumor aggressiveness and unsuccessful cancer treatments characterized by drug resistance, cancer recurrence, and poor survival rates.[32] Therefore, HIF- $1 \alpha$ and related proteins may serve as an effective radiotherapeutic target.

The expression of VEGF in tumors is mainly driven by HIFmediated transcription in hypoxic cells. VEGF activates VEGF receptors on endothelial cells and triggers tyrosine kinase pathways that lead to angiogenesis. In tumor cells, VEGF signaling is characterized as autocrine,[33] and it is likely established with the help of hypoxia. The functions of VEGF in solid tumors are not limited to the stimulus of vasculogenesis and angiogenesis, but it also can increase vascular permeability[34] and enhance tumor growth and metastasis. Numerous studies have linked tumor VEGF overexpression to decreased overall survival and disease-free survival in cancer patients.[35]

Carbonic anhydrases are zinc metalloenzymes that catalyze the reversible hydration of carbon dioxide to carbonic acid. CAIX is a transmembrane protein that is expressed on the tumor cell membrane, and it is activated by HIF-1 $\alpha$.[36] It is overexpressed in von Hippel-Lindau (VHL) tumor suppressor gene mutated clear-cell renal cell carcinoma (ccRCC) and several other types of hypoxic solid tumors, but its expression is low in normal kidney and most other normal tissues.[7] CAIX is considered to be a biomarker of chronic tumor hypoxia,[8] and it may be involved in cell proliferation and transformation. [37] Together with the glycolysis product lactic acid, CAIX contributes to tumor extracellular acidification, a key feature of the solid tumor microenvironment that is a driving force for tumor progression and metastasis.

The influence of oxygen on the effect of radiotherapy was first recognized in the early twentieth century. Swartz observed that the reaction of skin to irradiation was less if the radiation source was pressed tight to the skin, implying that blood flow could modify the radiation response.[38] In a landmark study, Gray et al. observed that tumor cell viability was depressed 2.5 to three times more in air than in nitrogen by X-ray irradiation.[39] Now, it is a wellestablished concept that hypoxic cells are three-fold more resistant to radiation than oxygenic cells. [40,41]

With advances in methods to measure tumor hypoxia using Eppendorf polarographic electrodes[19,42] and bioreductive nitroimidazoles, $[43,44]$ substantial insight has been gained in the role and extent of hypoxia in tumors. In both head-and-neck and cervical cancers, the probability of achieving a complete response with radiotherapy was inversely correlated with hypoxic tumor volume.[45,46] A surgical series from Höckel et al. correlated the overall and disease-free survival of cervical cancer patients with $\mathrm{pO}_{2}$ levels, measured with the Eppendorf device, and found that tumor hypoxia may be correlated with the aggressiveness of the disease and may be a prognosticator for treatment outcome.[47] In high grade soft tissue sarcomas, Brizel et al. reported an association between tumor hypoxia and the development of metastases following multimodality treatment.[4] Furthermore, data acquired from 6,975 patients, accrued in 43 randomized trials, employing oxygen-mimicking sensitizers and hyperbaric oxygen, showed that treatment outcome was improved by reducing the influence of hypoxia.[48]

More severe tumor hypoxia has been correlated with increased distant metastases in human soft tissue sarcoma and earlier recurrence of glial brain tumors.[4,49] Graeber et al. reported that hypoxia induced apoptosis in oncogenically transformed cells and that further genetic alterations substantially reduced hypoxia-induced cell death.[50] This study demonstrated that tumor hypoxia provided selective pressure for an aggressive phenotype. The pathophysiologic consequences vary with the individual subtypes of acute or chronic hypoxia.[51] Classification of hypoxia subtypes may affect the radiotherapy schedule. For instance, modelling of acute and chronic hypoxia in non-small cell lung cancer (NSCLC) radiotherapy suggested that tumor control is dominated by chronic hypoxia for short hypofractionated treatments and by acute hypoxia for multifractionated treatments.[52]

\section{Simultaneous dose escalation in radiotherapy}

Progress in radiation dose delivery techniques, especially intensity-modulated radiation therapy (IMRT), makes possible sophisticated dose distribution strategies in the target volume. "Multidimensional radiotherapy" was proposed to take advantage of multimodality biological imaging and IMRT delivery in order to achieve biological conformality.[53] Using this approach, tumor hypoxia would constitute an important portion of the biological target, and this could be irradiated with escalated doses using a dose painting technique to improve the efficacy of radiotherapy. In contrast, the target volume of ordinary treatment plans receives a uniform dose. Dose painting can result in simultaneous escalated doses to the biological target, while the remainder of the target volume still receives the prescribed radiation dose. The concept of biological conformality was followed by investigating dose escalation targeting tumor hypoxia. [54,55]

Studies have shown that the uptake of hypoxia imaging agents correlated with radiation therapy outcome.[56] Dose escalation demands methods to accurately determine the spatial distribution of hypoxia within tumors that could yield valuable a priori information for the stratification of patients according to disease prognosis. Treatment planning studies using various positron-emitting hypoxia tracers and ${ }^{18} \mathrm{~F}-\mathrm{FDG}$ have shown the feasibility of the dose painting technique, e.g., the hypoxia subvolume dose is escalated to $150 \%$ of the prescribed dose.[57] In a feasibility study on hypoxia-guided IMRT dose escalation, 20 patients with headand-neck cancer underwent one ${ }^{18} \mathrm{~F}$-FDG PET/computed tomography $(\mathrm{CT})$ scan and three subsequent ${ }^{18} \mathrm{~F}-\mathrm{MISO} \mathrm{PET} / \mathrm{CT}$ scans. The PET images were co-registered with CT simulation images, and the hypoxia subvolume within the gross tumor volume (GTV) was delineated based on the ${ }^{18} \mathrm{~F}$-MISO images.[11] Higher doses ( $20 \%$ to $50 \%$ more than the primary GTV dose) were prescribed to the hypoxia subvolume, with one patient receiving an escalated dose of 105 Gy to the hypoxia subvolume. Currently there have been several clinical trials on hypoxia guided dose escalation. In 
Zhang M. et al: Targeting tumor hypoxia in radiotherapy

Table 1. PET imaging agents for tumor hypoxia, metabolism and proliferation. Some have been used in completed or ongoing clinical trials on simultaneous dose escalation (https://clinicaltrials.gov, accessed November 2015)

\begin{tabular}{|c|c|c|c|}
\hline Imaging agent & Uptake mechanism & Tumor assessment & Dose escalation \\
\hline${ }^{18} \mathrm{~F}-\mathrm{FDG}$ & Diffusion/active transport & A variety of cancers & H\&N; NPC; NSCLC; EC \\
\hline${ }^{18} \mathrm{~F}-\mathrm{MISO}$ & Bioreduction & Brain; Cervix; H\&N; Melanoma; NPC; Rectum & $\mathrm{H} \& \mathrm{~N} ; \mathrm{NPC}$ \\
\hline${ }^{18} \mathrm{~F}-\mathrm{EF} 5$ & Bioreduction & Brain; Breast; Cervix; H\&N; NSCLC; Prostate; Ovary; STS & \\
\hline${ }^{18} \mathrm{~F}-\mathrm{FLT}$ & Monophosphorylation & H\&N; Lung & $\mathrm{H} \& \mathrm{~N}$ \\
\hline${ }^{18} \mathrm{~F}-\mathrm{HX} 4$ & Bioreduction & Cervix; H\&N & NSCLC \\
\hline${ }^{18} \mathrm{~F}-\mathrm{FAZA}$ & Bioreduction & Breast; NSCLC & \\
\hline${ }^{18} \mathrm{~F}-\mathrm{VM} 4-037$ & CAIX binding & H\&N; Kidney; Liver; Lung; Stage 4 cancer & \\
\hline${ }^{64} \mathrm{Cu}-\mathrm{ATSM}$ & Bioreduction & Cervix; glioblastoma; NSCLC & \\
\hline${ }^{124}$ I-IAZGP & Bioreduction & Cervix; Rectum; Uterine & \\
\hline
\end{tabular}

EC, esophageal cancer; H\&N, head-and-neck cancer; NPC, nasopharyngeal carcinoma; NSCLC, non-small cell lung cancer; STS, soft tissue sarcoma

a phase II clinical trial in NSCLC (clinicaltrials.gov identifier: NCT01024829), patients were randomized between dose-escalation of the entire primary tumor or the high ${ }^{18} \mathrm{~F}$-FDG uptake region inside the primary tumor. Most of the patients could be escalated to $72 \mathrm{~Gy}$ while observing dose constraints to normal tissues.[58] Although this registered study includes an ${ }^{18} \mathrm{~F}-\mathrm{HX} 4$ imaging component, no report was found on how the hypoxia scan was used in clinical decisions. Table 1 summarizes the clinically investigated PET imaging agents for tumor hypoxia, metabolism and proliferation, and the dose escalation clinical trials using these agents. The next step would be to utilize multimodality functional imaging in radiation therapy planning.[59]

Regarding the simultaneous dose escalation regime, questions still remain: how to accurately measure the hypoxic fraction of tumors; which are more relevant to the therapeutic outcome; how to determine the escalated radiation doses that can properly address the radioresistance of hypoxic cells. For instance, targeting acute hypoxia might be more important than chronic hypoxia in cancer treatment because there is evidence that acutely hypoxic cells have a higher metastatic potential than chronically hypoxic cells.[60-62] Similarly, it has been hypothesized that cells at intermediate oxygen levels $(0.5$ to $20 \mathrm{mmHg})$ and acute hypoxia are important in tumor response to fractionated radiotherapy,[63] and knowledge of acute hypoxia could help improve cancer therapy regimes and, consequently, therapeutic outcomes. To date, there have been few reports on distinguishing acute and chronic hypoxia using medical imaging.[64] Comparative studies of hypoxia tracers in the same patient demonstrated high-uptake in the same tumor with good correlations; but the regions of high hypoxic agent retention only partially overlapped.[65,66] In clinical imaging studies, segmentation of the hypoxia subvolume is often based on arbitrary thresholds,[67] which results in uncertainties in the dose escalation target. Another issue with the dose escalation regime is the optimization of dose distribution; the studies on this topic are relatively sparse.[68] Not many patients have completed clinical trials on hypoxia imaging guided dose escalation. Presently, there are no sufficient outcome data to validate the dose escalation regimes, although in theory this approach may improve local control for tumors with more severe hypoxia.

\section{Hyperthermia in radiotherapy}

Hyperthermia has a long history of use in cancer therapy. In the late nineteenth century, Dr. Coley from New York Memorial Cancer Hospital treated cancer patients with artificial systemic hyperthermia for long periods, with a positive effect on overall five-year survival rate.[69] Later, heat was tested as a solo tumoricidal agent or in combination with radiotherapy or chemotherapy. The heat was administered for short periods but at much higher temperatures, in excess of $42{ }^{\circ} \mathrm{C}$. Subsequently, in vitro studies showed that the survival curves of heat-treated tumor cells were similar to that of irradiated cells,[70] and hyperthermia did not appear to be an effective tumoricidal agent on its own. When hyperthermia was used in combination with other therapy regimens, the best responses occurred at lower temperatures. Therefore, the focus of research shifted to mild temperature hyperthermia (MTH), with a temperature range of roughly 40.5 to $43.0^{\circ} \mathrm{C}$.[71]

A proper hyperthermia treatment causes dilation of local blood vessels and increases in blood perfusion. Animal studies have shown that MTH alone is capable of reducing tumor hypoxia in various types of tumors.[72,73] In treatment studies of animal tumors, hyperthermia was shown to improve median $\mathrm{pO}_{2}$ level and reduce hypoxic fraction in dogs with spontaneous soft tissue sarcomas[74] and to enhance the effect of radioimmunotherapy in nude mice bearing human colon cancer xenografts.[75] A recent study using murine tumor models showed that a mild elevation of body temperature resulted in therapeutically beneficial changes in the tumor microvascular function by sustained reduction in tumor interstitial fluid pressure and hypoxia.[76]

Clinical trials on MTH in combination with radiotherapy and/or chemotherapy found that the local control rate could be improved with combination therapy relative to monotherapy.[77] Jones et al. administered $40{ }^{\circ} \mathrm{C}, 60 \mathrm{~min}$ of hyperthermia to 12 patients with locally advanced cervical carcinoma on a weekly basis, approximately $30 \mathrm{~min}$ after external beam radiation, and achieved an excellent clinical response.[78] In a phase I/II study, 47 patients with locally advanced breast cancer received neoadjuvant treatment with liposomal doxorubicin, paclitaxel, and $41{ }^{\circ} \mathrm{C}, 60 \mathrm{~min}$ of hyperthermia followed by surgery and radiotherapy. It was reported that the 4-year disease-free survival of 43 evaluated patients was $63 \%$, and the 4 -year overall survival was $75 \%$.[79] A randomized study of 68 patients with post-operative local recurrent gastric carcinoma showed that abdominal hyperthermia combined with three-dimensional conformal radiotherapy yielded a higher response rate $(57.2 \%$ vs $47.1 \%)$, prolonged median local progression-free survival time (14 months vs 11 months), and improved immune function for post-operative recurrent gastric cancer.[80] 
MTH hardly exhibits cytotoxicity. Induction of chromosomal DNA strand breaks were not observed in cells heated at $43{ }^{\circ} \mathrm{C}$ for 30 or $60 \mathrm{~min}$, which is in opposition to cells irradiated with a dose as low as $0.15 \mathrm{~Gy}$.[81] However, hyperthermia is believed to interfere with radiation-induced signaling required for DNA double-strand break repair, thus resulting in increased cell death post irradiation.[82] Recently, it was reported that hyperthermia can sensitize glioma stem-like cells to radiation by inhibiting AKT signaling.[83] With the perspective of using hyperthermia with proton beam irradiation, it is hypothesized that the thermo-radiobiological advantages of hyperthermia coupled with proton dose distribution could possibly mimic carbon ion therapy.[84] One may expect that hyperthermia will gain widespread applications in combination with radiotherapy if it can be incorporated into the busy conventional radiotherapy schedule.

\section{Chemical radiosensitizers}

Early strategies for increasing the radiosensitivity of hypoxic tumor cells in radiotherapy included hyperbaric oxygen and chemical radiosensitizers. The most widely investigated and representative oxygen-mimetic radiosensitizers are the 2-nitroimidazoles, such as misonidazole and pimonidazole,[85] which undergo enzymaticand radiation-induced redox reactions. These chemicals have high electron affinity and mimic oxygen in "fixing" radiation damage caused by free radicals in an oxygen-deficient cell. In hypoxic tumor cells, nitroimidazoles undergo a series of enzymatic reductions mediated by nitroreductase enzymes that are expressed under hypoxic conditions, leading to the generation of highly reactive anion radicals, which then bind to thiol-containing cellular molecules. [86] In preclinical studies, misonidazole had a higher electron affinity and was more effective in sensitization of tumors to radiation without concomitant effects in normal tissues than the 5-nitroimidazole, metronidazole.[87,88] However, misonidazole performed poorly clinically due to dose-limiting neural toxicity of the radiosensitizers, which necessitated the employment of inadequate therapeutic doses. Not surprisingly, a few 2-nitroimidazoles and derivatives were later successfully used as hypoxia markers.[9-11]

Nimorazole, a 5-nitroimidazole, is a less effective radiosensitizer than misonidazole but its toxicity is much less, allowing for administration of large doses.[89,90] In a Danish study, 422 patients with invasive squamous cell carcinoma of the supraglottic larynx or pharynx were randomized to receive radiotherapy with nimorazole or placebo. The nimorazole group was reported to show a significantly better locoregional control rate than the placebo group (49\% vs 33\%).[91] An international multicenter randomized trial (IAEA-HypoX) suggested that locoregional tumor control and overall survival in patients with head and neck squamous cell carcinoma could be improved by combining nimorazole and accelerated radiotherapy.[92] Currently, there are ongoing randomized trials on the addition of nimorazole to radiotherapy in patients with locally advanced head-and-neck squamous cell carcinoma (clinicaltrials.gov identifiers: NCT01950689, NCT01880359).

Efaproxiral (RSR-13) is a synthetic allosteric modifier of hemoglobin that decreases hemoglobin-oxygen binding capacity, thereby facilitating oxygen release to tissues. Efaproxiral was shown to increase systemic and iliac vascular resistance in rats and to increase tissue oxygen delivery. $[93,94]$ Results from clinical trials with this drug, however, have demonstrated limited success. In a phase III clinical trial consisting of 515 patients with brain metastases, efaproxiral was found to mildly improve the median survival time when used as an adjunct to whole-brain radiation therapy, but the benefit was restricted to the subgroup of patients with breast cancer.[95] Thus, the use of efaproxiral as an adjunct to whole-brain radiotherapy for metastatic brain tumors was not recommended.[96]

Evofosfamide (Threshold Pharmaceuticals, Inc.), also known as TH-302, is an investigational hypoxia-activated prodrug designed to selectively target tumor hypoxia. TH-302 is a 2-nitroimidazole prodrug of the cytotoxin bromo-isophosphoramide mustard (BrIPM). The prodrug is activated only at very low levels of oxygen by a process that involves a single-electron reduction mediated by ubiquitous cellular reductases, such as the NADPH cytochrome $\mathrm{P} 450$, to generate a radical anion prodrug. In the presence of oxygen, the radical anion prodrug reacts rapidly with oxygen to generate the original prodrug and superoxide. Therefore, TH-302 is relatively inert under normal oxygen conditions, remaining intact as a prodrug; when exposed to severe hypoxic conditions, however, the radical anion undergoes irreversible fragmentation, releasing the active drug Br-IPM and an azole derivative. The released cytotoxin Br-IPM alkylates DNA, inducing intrastrand and interstrand crosslinks.[97] TH-302 is being evaluated in clinical trials for the treatment of multiple tumor types as a monotherapy and in combination with chemotherapeutic agents and other targeted cancer drugs.[98] In recently reported animal studies, TH-302 enhanced the effects of VEGF-A inhibition and radiation on sarcoma xenografts;[99] the combination of TH-302 and radiotherapy further increased the growth delay of rhabdomyosarcoma R1 and H460 non-small cell lung cancer tumors than TH-302 treatment alone. [100] These results suggest that the combination of TH-302 and radiotherapy might warrant clinical testing in human patients.

Hypoxic-activated cytotoxins include mitomycins, porfiromycin, apaziquone, tirapazamine, and AQ4N. These compounds are used in order to exploit tumor hypoxia, and their use is based on the hypothesis that the oxygenation status of malignant cells can be turned into a clinical advantage. Conceptually, compounds that are converted to cytotoxic agents under low oxygen concentrations should be effective radiosensitizers for hypoxic tumor cells. Mitomycin C induces DNA cross-links through alkylation, thus inhibiting DNA and RNA synthesis, and it has been approved for the treatment of disseminated gastric cancer or pancreatic cancer. Mitomycin C lacks preferential selectivity for hypoxic cells; and, in clinical trials, it was administered once or twice during a radiotherapy course.[101] The ARO 95-06 randomized trial compared hyperfractionated accelerated chemoradiation with mitomycin C/5-fluorouracil (C-HART) with hyperfractionated accelerated radiation therapy (HART) alone in locally advanced head-and-neck cancer. Long-term results showed that C-HART remains superior to HART in terms of locoregional control and survival rates.[102]

Tirapazamine or TPZ (SR-4233) has a 1,2,4-benzotriazine-1,4 dioxide group that is susceptible to bioreduction.[103] TPZ is 15200 fold more toxic to hypoxic than oxic cells in culture due to a one-electron reduction to a DNA-damaging free radical that is stabilized under hypoxic conditions and can act as a potent cytotoxic agent.[104] In both in vivo and in vitro settings, TPZ was found to substantially enhance radiation-induced cell death in a single-dose regimen and fractionated radiation treatment, particularly in hypoxic cells. Despite these preliminary encouraging results, several phase III trials have failed to demonstrate any benefit upon addition of TPZ to chemotherapy or radiation therapy in response rate, overall survival, or progression-free survival of NSCLC, headand-neck cancer, or cervical carcinoma.[105]

The alkylaminoanthraquinone N-oxide AQ4N (banoxantrone) was designed as an antitumor prodrug with little intrinsic activity. Once reduced by cytochrome P450 enzymes, particularly CYP3A, it releases a stable and persistent cytotoxin, AQ4, a potent DNA 
Zhang M. et al: Targeting tumor hypoxia in radiotherapy

Table 2. Representative chemical radiosensitizers and therapeutic agents targeting hypoxic tumor cells

\begin{tabular}{|c|c|c|}
\hline Compound & Mechanisms & Characteristics \\
\hline Misonidazole & $\begin{array}{l}\text { Bioreduction; fixing damage of free radicals; depletion of } \\
\text { radioprotective thiols }\end{array}$ & 2-nitroimidazole; high electron affinity; neural toxicity \\
\hline Nimorazole & Same as above & $\begin{array}{l}\text { 5-nitroimidazole; less effective than misonidazole; } \\
\text { much less toxic }\end{array}$ \\
\hline Efaproxiral & $\begin{array}{l}\text { Decreasing hemoglobin-oxygen binding capacity; } \\
\text { facilitating oxygen release to tissues }\end{array}$ & Allosteric modifier of hemoglobin \\
\hline TH-302 & $\begin{array}{l}\text { Activated in hypoxia; releasing potent DNA alkylating agent } \\
\text { Br-IPM }\end{array}$ & 2-nitroimidazole prodrug \\
\hline Mitomycin C & $\begin{array}{l}\text { Hypoxia activated cytotoxin; inducing DNA cross-links } \\
\text { through alkylation }\end{array}$ & Lacking selectivity for hypoxic cells \\
\hline Cisplatin & $\begin{array}{l}\text { Producing interstrand DNA crosslinks; scavenging of } \\
\text { hydrated electrons; formation of } \mathrm{OH} \text { radicals }\end{array}$ & $\begin{array}{l}\text { Platinum-containing chemotherapy drug; various } \\
\text { side-effects }\end{array}$ \\
\hline Tirapazamine & $\begin{array}{l}\text { Activated in hypoxia; producing hydroxyl or benzotriazinyl } \\
\text { radicals }\end{array}$ & Much more toxic to hypoxic than oxic cells \\
\hline AQ4N & $\begin{array}{l}\text { Reduced by cytochrome P450 enzymes; releasing cytotoxin } \\
\text { AQ4 }\end{array}$ & Antitumor prodrug; little intrinsic activity \\
\hline PX-478 & $\begin{array}{l}\text { Suppressing hypoxia inducible factor (HIF)- } 1 \alpha \text { levels and } \\
\text { HIF-1 } \alpha \text { target genes expression; enhancing radiosensitivity }\end{array}$ & Inhibitor of HIF-1 $\alpha$ \\
\hline $\mathrm{EZN}-2968$ & Inhibiting HIF-1 $\alpha$ expression & Antisense of HIF-1 $\alpha$ \\
\hline Bevacizumab & Inhibiting VEGF-A and blocking angiogenesis & $\begin{array}{l}\text { Monoclonal antibody of VEGF-A; potential } \\
\text { radioimmunotherapy agent }\end{array}$ \\
\hline Girentuximab & Inhibiting CAIX; disrupting $\mathrm{pH}$ regulation & $\begin{array}{l}\text { Monoclonal antibody of CAIX; diagnostic and } \\
\text { therapeutic agent of ccRCC }\end{array}$ \\
\hline
\end{tabular}

intercalator and topoisomerase II inhibitor.[106,107] In preclinical models bearing mammary carcinoma, AQ4N was shown to interact additively with radiation, both in single-fraction irradiation and fractionated schedules.[108] AQ4N was investigated in phase I and phase II trials as a single agent or in combination with radiation and temozolomide (clinicaltrials.gov identifier: NCT00394628). However, results from the combination trials with radiation have not yet been reported.

\section{Therapeutic agents targeting hypoxia}

Monoclonal antibodies have been developed to target hypoxic cells or hypoxia pathways for tumor imaging and therapeutic purposes. Bevacizumab is a recombinant humanized monoclonal antibody that blocks angiogenesis by inhibiting VEGF-A,[109] the first clinically available angiogenesis inhibitor in the United States. It was first approved in 2004 by the U.S. Food and Drug Administration for combination use with standard chemotherapy for metastatic colon cancer. It has since been approved for use in certain lung cancers, renal cancers, ovarian cancers, and glioblastoma multiforme of the brain. Bevacizumab is on the World Health Organization's List of Essential Medicines for its use in treating certain eye diseases. Radioimmunoconjugates comprised of bevacizumab conjugated with the gamma-emitting radioisotopes bind to VEGF, allowing non-invasive detection of VEGF distribution in animal models with human ovarian tumor xenograft,[110] as well as in melanoma patients.[111] A preliminary study with the SKOV-3 ovarian cancer cell line and male mice suggested that ${ }^{131}$ I-bevacizumab is a potential radioimmunotherapy agent for ovarian cancer.[112]
HIF-1 inhibitors may suppress tumor resistance to therapy through various intricate mechanisms. PX-478, an orally administered inhibitor of HIF-1 $\alpha$ expression, was reported to suppress HIF-1 $\alpha$ levels in human tumor xenografts and inhibit the expression of HIF-1 target genes, including VEGF and the glucose transporter-1.[113] It was reported that PX-478 inhibited HIF-1 $\alpha$ protein levels and HIF-1 transactivating activity in a variety of cancer cell lines in both normoxic and hypoxic conditions.[114,115] PX-478 enhanced radiosensitivity of prostate carcinoma cells. [114,116] EZN-2968, an antisense oligonucleotide inhibitor of HIF- $1 \alpha$ expression, binds HIF- $1 \alpha$ mRNA with high affinity, causing its downregulation and a consequent reduction in HIF-1 $\alpha$ protein level. In vivo and in vitro data showed potent downregulation of HIF-1 $\alpha$ and VEGF mRNAs and inhibition of tumor cell growth following the administration of EZN-2968.[117] A proof of concept pilot trial with EZN-2968 demonstrated safety and potential activity in patients with refractory advanced solid tumors.[118] Radiation can induce high HIF-1 $\alpha$ expression upon reoxygenation, [119] and it has been hypothesized that blocking HIF-1 $\alpha$ following radiotherapy may prolong and enhance the immune effects of radiotherapy.[120] In sarcoma mouse models, trimodality therapy with radiotherapy, VEGF-A inhibition, and HIF-1 $\alpha$ inhibition using short hairpin RNA or doxorubicin maximized the effects of radiation through destruction of tumor vasculature.[121] BAY-847296, an inhibitor of mitochondrial complex I and HIF-1 activity, has been shown to enhance tumor control after single-dose irradiation of human squamous cell carcinomas in nude mice.[122]

Monoclonal antibodies or CAIX-specific inhibitors are used to disrupt $\mathrm{pH}$ regulation by cancer cells, further impairing tumor growth and metastasis. Girentuximab (trade name Rencarex ${ }^{\circledR}$, Wilex $A G)$ is a chimeric monoclonal antibody that was designed for 


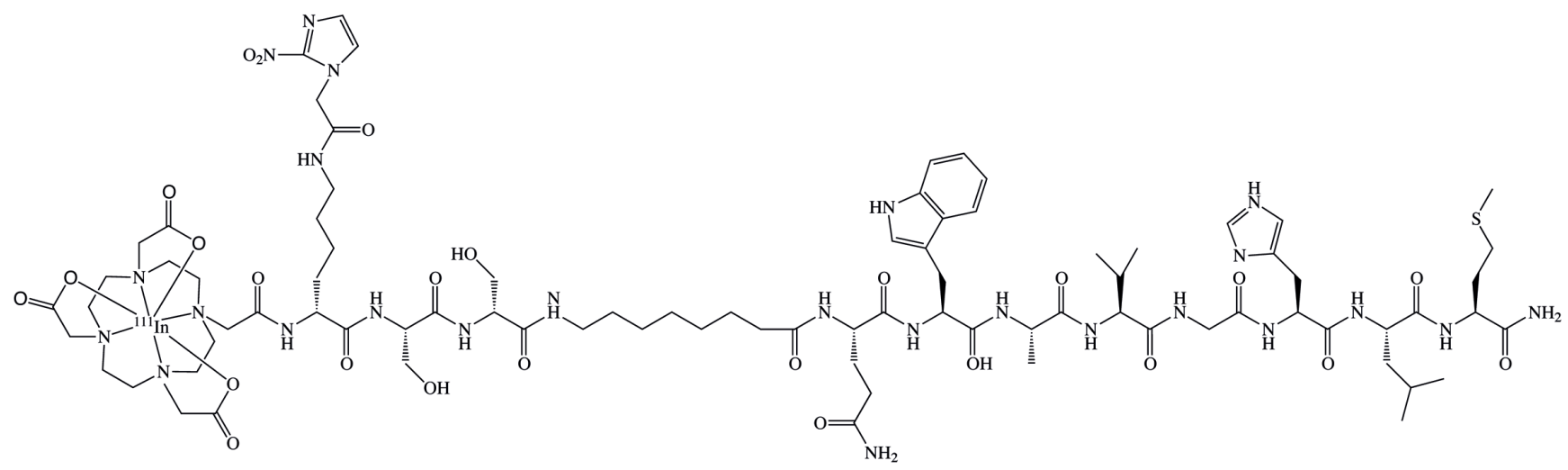

Fig. 3. Hypoxia enhanced ${ }^{111}$ In-BB2r-targeted conjugate, including a chelating agent (DOTA) that forms a complex with the radiometal ( ${ }^{111}$ In), a linker (8-Aminooctanoic acid) for the covalent attachment of the peptide, a hypoxia trapping agent (2-nitroimidazole), and a $\mathrm{BB}_{2} \mathrm{r}$-targted peptide $\mathrm{BN}(7-14) \mathrm{NH}_{2}$.

the treatment of renal cell carcinoma, and it binds specifically to the protein structure of CAIX.[123,124] In a phase III trial with Rencarex to treat ccRCC, Rencarex treatment did not improve median disease-free survival compared with placebo; however, further subgroup analysis revealed that the Rencarex effect became more pronounced for higher CAIX scores (http://www.wilex.de/ portfolio-english/rencarex/phase-iii-ariser/\#Status, accessed June 2015). A phase I radioimmunotherapy study with ${ }^{177} \mathrm{Lu}$-labeled girentuximab showed that the drug is well tolerated in metastatic ccRCC patients[125]; this was followed by a phase II study in patients with advanced renal cancer (clinicaltrials.gov identifier: NCT02002312). Radiolabeled girentuximab is valued in the presurgical diagnosis and characterization of ccRCC patients.[126,127] There is a significant correlation between in vivo PET/CT images and in vitro measurements of the uptake of ${ }^{124}$ I-labeled girentuximab in ccRCC patients.[128] A phase III trial was designed to determine whether the combination of ${ }^{124}$ I-labeled girentuximab with PET/CT could improve the diagnosis of renal masses versus $\mathrm{CT}$ alone. The role of ${ }^{111} \mathrm{In}$-labeled girentuximab in the evaluation of the therapeutic effect of small renal masses is currently being investigated (clinicaltrials.gov identifier: NCT02411968). Representative chemical radiosensitizers and therapeutic agents targeting tumor hypoxia are summarized in Table 2.

\section{Hypoxia-selective trapping agents}

Receptor-targeted peptidic radiopharmaceuticals have been extensively investigated.[129,130] These radiotracers have desirable pharmacokinetics properties, including the ability to rapidly accumulate at the target site, rapidly clear from plasma, and exhibit good tumor penetration. However, the usefulness of many receptortargeted peptides is limited by the relatively poor residence time in the tumor, due to metabolism and efflux and diffusion from the tissue. Poor retention of targeted radiotherapeutics at the tumor site might not affect uptake but may lead to a markedly lower cumulative therapeutic dose delivered to the tumor and, consequently, a reduction in the translational potential of the agents to the clinic.

Recently, efforts have been reported that take advantage of the hypoxic nature of many tumors to selectively increase the tumor residence time of receptor-targeted peptides. Garrison et al. incorporated 2-nitroimidazoles, which are known to be trapped bioreductively in hypoxic cells, into the bombesin (BN) peptide (Fig. 3 ), an amphibian peptide that targets the gastrin-releasing peptide receptor (BB2r) with nanomolar affinity.[131] The overarching idea behind this approach is depicted in Fig. 4. Specifically, this work is focused on prostate cancer, which has been shown to be among the most hypoxic types of tumors observed clinically.

Bombesin or gastrin-releasing peptide regulates numerous functions of the gastrointestinal and central nervous systems, and the effects of bombesin are mediated through the BB2r. In humans, the BB2r is expressed in the pancreas and, at much lower levels, in the stomach, adrenal glands, and brain. The BB2r has been shown to be expressed at higher densities on a variety of human tumors, such as those of the breast, lung, colon, and prostate, relative to normal tissues.[132] Upon binding of the BB2r-targeted agent to the receptor, the receptor-ligand complex becomes internalized. Under hypoxic conditions, the 2-nitroimidazole(s) attached to the targeted peptide becomes activated and capable of binding irreversibly to intracellular nucleophiles, such as proteins. Given the hypoxic burden of tumors in prostate cancer patients, the expectation is that the activation and irreversible binding to the intracellular contents of hypoxic cells will substantially and selectively increase the residence time of BB2r and other receptor-targeted peptides in hypoxic tumors, thereby leading to an increase in the diagnostic and therapeutic efficacy and clinical potential.

Based on these rationales, ${ }^{111}$ In-labeled $\mathrm{BN}(7-14)$ conjugates, composed of 2-nitroimidazole moieties, were synthesized and evaluated both in vitro and in vivo. Internalization and efflux studies on PC-3 cells demonstrated significantly lower clearance rate of the radioconjugates containing 2-nitroimidazole relative to control under hypoxic conditions. Up to 2-fold higher macromolecule associated radioactive signals were observed for the 2-nitroimidazole-containing conjugates under hypoxic conditions, suggesting that the significant increase in retention was at least partially due to the irreversible binding of 2-nitroimidazoles to intracellular proteins. The in vivo biodistribution on PC-3 tumor-bearing severe combined immunodeficiency (SCID) mice demonstrated up to $20 \%$ higher tumor retention for the 2-nitroimidazole hypoxia trapping enhanced radioconjugates. These results indicate the great potential for the use of hypoxia-selective trapping agents to improve the tumor retention of various radiolabeled targeting agents.

\section{Prospects}

Tumor hypoxia is a complicated and stubborn obstacle to radiation therapy. Recently, there has been progress in the areas reviewed in this article; however, attempts to overcome tumor hypoxia and the resultant resistance to radiotherapy have only achieved lim- 


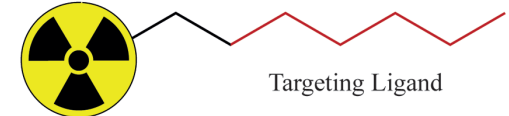

Radionuclide
Hypoxia Trapping Agent

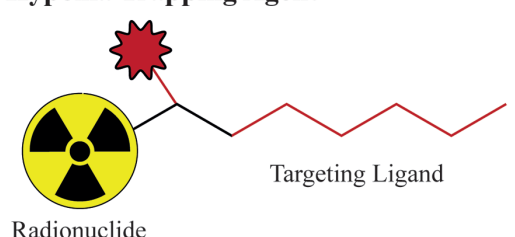

Radionuclide

Traditional Bombesin Conjugates

Hypoxia Endanced Bombesin Conjugates

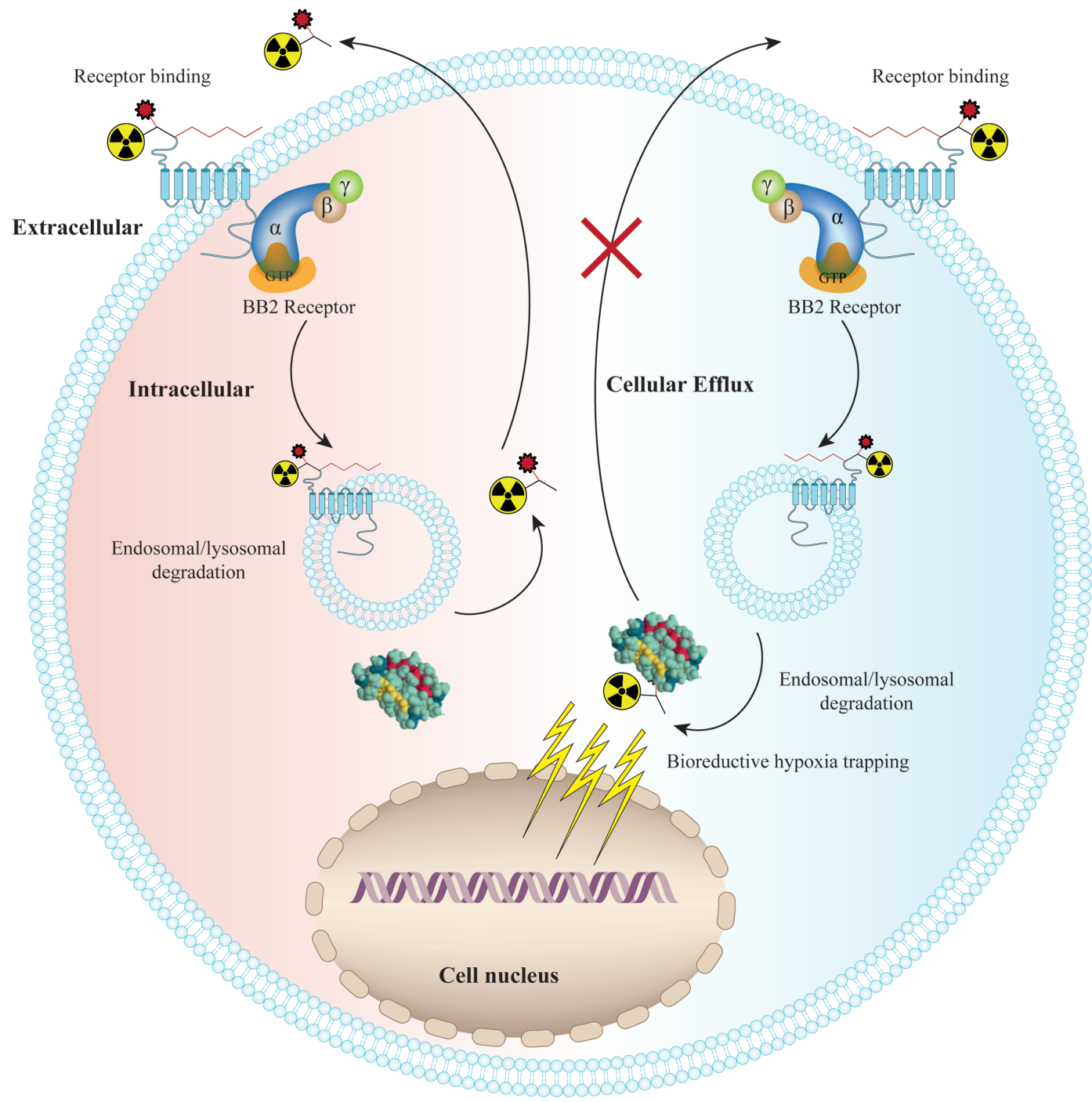

Fig. 4. Expected trapping mechanism of hypoxia enhanced ${ }^{111}$ In-BB2r-targeted conjugates.

ited success. Previous experiences suggest that targeting tumor hypoxia with a single treatment modality or therapeutic agent may be insufficient.

We hypothesize that the next successful move in the battle against tumor hypoxia will be biologically guided intensity-modulated radiotherapy. This concept is not restricted to dose escalation treatment planning based on hypoxia imaging. By utilizing multidimensional molecular imaging agents and biomarkers, this approach will achieve two essential goals: first, to identify the vi- able and hypoxic tumor cells that are most relevant to the poor prognosis of the disease; second, to stratify patients who will most likely benefit from this treatment modality. Molecular imaging using radiolabeled hypoxia tracers or hypoxia related biomarkers will play a central role for cancer diagnosis and delineation of the tracer-specific therapeutic volume, as well as characterization of therapeutic agents in vivo. In this formula, the most difficult component is the identification of predictive genomic signatures.

We predict in the foreseeable future that tumor hypoxia-targeted 
therapy will benefit select patients through a combination of external beam radiotherapy and molecular therapeutic agents and/or radiosensitizers. While precise delivery of escalated radiation doses to hypoxic tumor cells may be associated with better outcomes, in the long run, biological breakthroughs are expected to provide the ultimate solution to cancer therapy.

\section{Acknowledgements}

The study of BB2r-targeted radiotherapy for prostate cancer is funded by the National Cancer Institute (project number: 5R01CA179059-02; principal investigator: Jered Garrison, PhD).

\section{Conflict of interest}

None.

\section{Author contributions}

Designing the outline of this review (MZ, ZHZ, JG); drafting the manuscript (MZ, ZYZ, ZHZ); collecting related information and editing the manuscript (ZYZ, ZHZ, JG).

\section{References}

[1] Vaupel P, Harrison L. Tumor hypoxia: Causative factors, compensatory mechanisms, and cellular response. Oncologist 2004;9(Suppl 5):4-9.

[2] Thomlinson RH, Gray LH. The histological structure of some human lung cancers and the possible implications for radiotherapy. Br J Cancer 1955;9:539-49. doi: 10.1038/bjc. 1955.55 .

[3] Teicher BA. Hypoxia and drug resistance. Cancer Metastasis Rev 1994;13:13968. doi: 10.1007/BF00689633.

[4] Brizel DM, Scully SP, Harrelson JM, Layfield LJ, Bean JM, Prosnitz LR, et al. Tumor oxygenation predicts for the likelihood of distant metastases in human soft tissue sarcoma. Cancer Res 1996;56:941-3.

[5] Vaupel P, Frinak S, O'Hara M. Direct measurement of reoxygenation in malignant mammary tumors after a single large dose of irradiation. Adv Exp Med Biol 1984;180:773-82. doi: 10.1007/978-1-4684-4895-5 76.

[6] Urano M, Chen Y, Humm J, Koutcher JA, Zanzonico P, Ling C. Measurements of tumor tissue oxygen tension using a time-resolved luminescencebased optical oxylite probe: Comparison with a paired survival assay. Radiat Res 2002;158:167-73. doi: 10.1667/0033-7587(2002)158[0167:MOTTOT]2.0 $\mathrm{CO} ; 2$.

[7] Wykoff CC, Beasley NJ, Watson PH, Turner KJ, Pastorek J, Sibtain A, et al. Hypoxia-inducible expression of tumor-associated carbonic anhydrases. Cancer Res 2000;60:7075-83.

[8] Vordermark D, Kaffer A, Riedl S, Katzer A, Flentje M. Characterization of carbonic anhydrase IX (CA IX) as an endogenous marker of chronic hypoxia in live human tumor cells. Int J Radiat Oncol Biol Phys 2005;61:1197-207. doi: 10.1016/j.ijrobp.2004.11.031

[9] Raleigh JA, Calkins-Adams DP, Rinker LH, Ballenger CA, Weissler MC, Fowler WCJr, et al. Hypoxia and vascular endothelial growth factor expression in human squamous cell carcinomas using pimonidazole as a hypoxia marker. Cancer Res 1998;58:3765-8.

[10] Valk PE, Mathis CA, Prados MD, Gilbert JC, Budinger TF. Hypoxia in human gliomas: demonstration by PET with fluorine-18-fluoromisonidazole. J Nucl Med 1992;33:2133-7.

[11] Lee NY, Mechalakos JG, Nehmeh S, Lin Z, Squire OD, Cai S, et al. Fluorine-18-labeled fluoromisonidazole positron emission and computed tomography-guided intensity-modulated radiotherapy for head and neck cancer: a feasibility study. Int J Radiat Oncol Biol Phys 2008;70:2-13. doi: 10.1016/j. ijrobp.2007.06.039.

[12] McQuade P, Martin KE, Castle TC, Went MJ, Blower PJ, Welch MJ, et al. Investigation into ${ }^{64} \mathrm{Cu}$-labeled bis(selenosemicarbazone) and bis(thiosemicarbazone) complexes as hypoxia imaging agents. Nucl Med Biol 2005;32:147-56. doi: 10.1016/j.nucmedbio.2004.10.004.

[13] Gallez B, Baudelet C, Jordan BF. Assessment of tumor oxygenation by elec- tron paramagnetic resonance: principles and applications. NMR Biomed 2004;17:240-62. doi: 10.1002/nbm.900.

[14] Mayr NA, Yuh WT, Magnotta VA, Ehrhardt JC, Wheeler JA, Sorosky JI, et al. Tumor perfusion studies using fast magnetic resonance imaging technique in advanced cervical cancer: a new noninvasive predictive assay. Int J Radia Oncol Biol Phys 1996;36:623-33. doi: 10.1016/S0360-3016(97)85090-0.

[15] Li XF, Carlin S, Urano M, Russell J, Ling CC, O’Donoghue JA. Visualization of hypoxia in microscopic tumors by immunofluorescent microscopy. Cancer Res 2007;67:7646-53. doi: 10.1158/0008-5472.CAN-06-4353.

[16] Folkman J, Merler E, Abernathy C, Williams G. Isolation of a tumor factor responsible for angiogenesis. J Exp Med 1971;133:275-88. doi: 10.1084/ jem.133.2.275

[17] Vajkoczy P, Farhadi M, Gaumann A, Heidenreich R, Erber R, Wunder A, et al. Microtumor growth initiates angiogenic sprouting with simultaneous expression of VEGF, VEGF receptor-2, and angiopoietin-2. J Clin Invest 2002;109:777-85. doi: 10.1172/JCI0214105.

[18] Nöth U, Rodrigues LM, Robinson SP, Jork A, Zimmermann U, Newell B, et al. In vivo determination of tumor oxygenation during growth and in response to carbogen breathing using 15C5-loaded alginate capsules as fluorine-19 magnetic resonance imaging oxygen sensors. Int $\mathrm{J}$ Radiat Oncol Biol Phys 2004;60:909-19. doi: 10.1016/j.ijrobp.2004.07.671.

[19] Brizel DM, Rosner GL, Harrelson J, Prosnitz LR, Dewhirst MW. Pretreatment oxygenation profiles of human soft tissue sarcomas. Int J Radiat Oncol Bio Phys 1994;30:635-42. doi: 10.1016/0360-3016(92)90950-M.

[20] Koch C, Evans S. Optimizing hypoxia detection and treatment strategies. Semin Nucl Med 2015;42:163-76.

[21] Koch C, Jenkins W, Jenkins K, Yang X, Shuman A, Pickup S, et al. Mechanisms of blood flow and hypoxia production in rat 9L-epigastric tumors. Tumor Microenviron Ther 2013;1:1-13.

[22] Koukourakis MI, Giatromanolaki A, Sivridis E, Fezoulidis I. Cancer vascularization: implications in radiotherapy? Int J Radiat Oncol Biol Phys 2000;48:545-53. doi: 10.1016/S0360-3016(00)00677-5

[23] Dewhirst MW, Braun RD, Lanzen JL. Temporal changes in $\mathrm{PO}_{2}$ of R3230AC tumors in Fischer-344 rats. Int J Radiat Oncol Biol Phys 1998;42:723-6. doi: 10.1016/S0360-3016(98)00304-6.

[24] Brurberg KG, Graff BA, Rofstad EK. Temporal heterogeneity in oxygen tension in human melanoma xenografts. Br J Cancer 2003;89:350-6. doi: 10.1038 sj.bjc. 6601047 .

[25] Warburg O. On the origin of cancer cells. Science 1956;123:309-14. doi: 10.1126/science.123.3191.309.

[26] Flier JS, Mueckler MM, Usher P, Lodish HF. Elevated levels of glucose transport and transporter messenger RNA are induced by ras or src oncogenes. Science 1987;235:1492-5. doi: 10.1126/science.3103217.

[27] Osthus RC, Shim H, Kim S, Li Q, Reddy R, Mukherjee M, et al. Deregulation of glucose transporter 1 and glycolytic gene expression by c-myc. J Biol Chem 2000;275:21797-800. doi: 10.1074/jbc.C000023200.

[28] Rajendran JG, Mankoff DA, O’Sullivan F, Peterson LM, Schwartz DL, Conrad EU, et al. Hypoxia and glucose metabolism in malignant tumors: Evaluation by $\left[{ }^{18} \mathrm{~F}\right]$ fluoromisonidazole and $\left[{ }^{18} \mathrm{~F}\right]$ fluorodeoxyglucose positron emission tomography imaging. Clin Cancer Res 2004;10:2245-52. doi: 10.1158/10780432.CCR-0688-3.

[29] Wang GL, Semenza GL. General involvement of hypoxia-inducible factor 1 in transcriptional response to hypoxia. Proc Natl Acad Sci U S A 1993;90:4304-8. doi: 10.1073/pnas.90.9.4304

[30] Jiang BH, Rue E, Wang GL, Roe R, Semenza GL. Dimerization, DNA binding, and transactivation properties of hypoxia-inducible factor 1. J Biol Chem 1996;271:17771-8. doi: 10.1074/jbc.271.30.17771.

[31] Jiang BH, Semenza GL, Bauer C, Marti HH. Hypoxia-inducible factor 1 levels vary exponentially over a physiologically relevant range of $\mathrm{O}_{2}$ tension. Am J Physiol 1996;271:C1172-80.

[32] Semenza GL. Targeting HIF-1 for cancer therapy. Nat Rev Cancer 2003;3:72132. doi: $10.1038 / \mathrm{nrc} 1187$.

[33] Perrot-Applanat M, Di Benedetto M. Autocrine functions of VEGF in breast tumor cells: adhesion, survival, migration and invasion. Cell Adh Migr 2012;6:547-53. doi: 10.4161/cam.23332.

[34] Senger DR, Galli SJ, Dvorak AM, Perruzzi CA, Harvey VS, Dvorak HF. Tumor cells secrete a vascular permeability factor that promotes accumulation of ascites fluid. Science 1983;219:983-5. doi: 10.1126/science.6823562.

[35] Poon RT, Fan ST, Wong J. Clinical implications of circulating angiogenic factors in cancer patients. J Clin Oncol 2001;19:1207-25.

[36] Grabmaier K, A de Weijert MC, Verhaegh GW, Schalken JA, Oosterwijk E. Strict regulation of CAIX ${ }^{\mathrm{G} 250 / \mathrm{MN}}$ by HIF-1 $\alpha$ in clear cell renal cell carcinoma. Oncogene 2004;23:5624-31. doi: 10.1038/sj.onc.1207764.

[37] Pastorek J, Pastorekova S, Callebaut I, Mornon JP, Zelnik V, Opavsky R, et al. Cloning and characterization of $\mathrm{MN}$, a human tumor-associated protein with a domain homologous to carbonic anhydrase and a putative helix-loop-helix DNA binding segment. Oncogene 1994;9:2877-88.

[38] Bernier J, Hall EJ, Giaccia A. Radiation oncology: a century of achievements. Nat Rev Cancer 2004;4:737-47. doi: 10.1038/nrc1451.

[39] Gray LH, Conger AD, Ebert M, Hornsey S, Scott OC. The concentration of 
oxygen dissolved in tissues at the time of irradiation as a factor in radiotherapy. Br J Radiol 1953;26:638-48. doi: 10.1259/0007-1285-26-312-638.

[40] Ling CC, Michaels HB, Gerweck LE, Epp ER, Peterson EC. Oxygen sensitization of mammalian cells under different irradiation conditions. Radiat Res 1981;86:325-40. doi: 10.2307/3575509.

[41] Kwok TT, Sutherland RM. The radiation response of cells recovering after chronic hypoxia. Radiat Res 1989;119:261-7. doi: 10.2307/3577618.

[42] De Jaeger K, Merlo FM, Kavanagh MC, Fyles AW, Hedley D, Hill RP. Heterogeneity of tumor oxygenation: relationship to tumor necrosis, tumor size, and metastasis. Int J Radiat Oncol Biol Phys 1998;42:717-21. doi: 10.1016/S03603016(98)00323-X

[43] Bentzen L, Keiding S, Nordsmark M, Falborg L, Hansen SB, Keller J, et al. Tumour oxygenation assessed by ${ }^{18} \mathrm{~F}$-fluoromisonidazole pet and polarographic needle electrodes in human soft tissue tumours. Radiother Oncol 2003;67:33944. doi: 10.1016/S0167-8140(03)00081-1.

[44] Rajendran JG, Wilson DC, Conrad EU, Peterson LM, Bruckner JD, Rasey JS, et al. $\left[{ }^{18} \mathrm{~F}\right] \mathrm{FMISO}$ and $\left[{ }^{18} \mathrm{~F}\right] \mathrm{FDG}$ PET imaging in soft tissue sarcomas: correlation of hypoxia, metabolism and VEGF expression. Eur J Nucl Med Mol Imaging 2003;30:695-704 doi: 10.1007/s00259-002-1096-7.

[45] Höckel M, Schlenger K, Mitze M, Schaffer U, Vaupel P. Hypoxia and radiation response in human tumors. Semin Radiat Oncol 1996;6:3-9. doi: 10.1016/ S1053-4296(96)80031-2.

[46] Lyng H, Sundfor K, Rofstad EK. Changes in tumor oxygen tension during radiotherapy of uterine cervical cancer: relationships to changes in vascular density, cell density, and frequency of mitosis and apoptosis. Int J Radiat Oncol Biol Phys 2000;46:935-46. doi: 10.1016/S0360-3016(99)00497-6.

[47] Höckel M, Schlenger K, Aral B, Mitze M, Schaffer U, Vaupel P. Association between tumor hypoxia and malignant progression in advanced cancer of the uterine cervix. Cancer Res 1996;56:4509-15.

[48] Overgaard J, Horsman MR. Modification of hypoxia-induced radioresistance in tumors by the use of oxygen and sensitizers. Semin Radiat Oncol 1996;6:10-21. doi: 10.1016/S1053-4296(96)80032-4.

[49] Evans SM, Judy KD, Dunphy I, Jenkins WT, Hwang WT, Nelson PT, et al. Hypoxia is important in the biology and aggression of human glial brain tumors. Clin Cancer Res 2004;10:8177-84. doi: 10.1158/1078-0432.CCR-04-1081.

[50] Graeber TG, Osmanian C, Jacks T, Housman DE, Koch CJ, Lowe SW, et al. Hypoxia-mediated selection of cells with diminished apoptotic potential in solid tumours. Nature 1996;379:88-91. doi: 10.1038/379088a0.

[51] Bayer C, Shi K, Astner ST, Maftei CA, Vaupel P. Acute versus chronic hypoxia: why a simplified classification is simply not enough. Int $\mathrm{J}$ Radiat Oncol Biol Phys 2011;80:965-8. doi: 10.1016/j.ijrobp.2011.02.049.

[52] Ruggieri R. Hypofractionation in non-small cell lung cancer (NSCLC): suggestions from modelling both acute and chronic hypoxia. Phys Med Biol 2004;49:4811-23. doi: 10.1088/0031-9155/49/20/011.

[53] Ling CC, Humm J, Larson S, Amols H, Fuks Z, Leibel S, et al. Towards multidimensional radiotherapy (MD-CRT): biological imaging and biological conformality. Int J Radiat Oncol Biol Phys 2000;47:551-60. doi: 10.1016/S03603016(00)00467-3.

[54] Lin Z, Mechalakos J, Nehmeh S, Schoder H, Lee N, Humm J, et al. The influence of changes in tumor hypoxia on dose-painting treatment plans based on ${ }^{18} \mathrm{~F}$-FMISO positron emission tomography. Int J Radiat Oncol Biol Phys 2008;70:1219-28. doi: 10.1016/j.ijrobp.2007.09.050.

[55] Chao KS, Bosch WR, Mutic S, Lewis JS, Dehdashti F, Mintun MA, et al. A novel approach to overcome hypoxic tumor resistance: $\mathrm{Cu}$-ATSM-guided intensitymodulated radiation therapy. Int J Radiat Oncol Biol Phys 2001;49:1171-82. doi: 10.1016/S0360-3016(00)01433-4.

[56] Thorwarth D, Eschmann SM, Holzner F, Paulsen F, Alber M. Combined uptake of $\left[{ }^{18} \mathrm{~F}\right] \mathrm{FDG}$ and $\left[{ }^{18} \mathrm{~F}\right] \mathrm{FMISO}$ correlates with radiation therapy outcome in head-and-neck cancer patients. Radiother Oncol 2006;80:151-6. doi: 10.1016/j. radonc.2006.07.033

[57] Clausen MM, Hansen AE, Lundemann M, Hollensen C, Pommer T, Munck Af Rosenschöld P, et al. Dose painting based on tumor uptake of Cu-ATSM and FDG: a comparative study. Radiat Oncol 2014;9:228. doi: 10.1186/s13014-0140228-0.

[58] van Elmpt W, De Ruysscher D, van der Salm A, Lakeman A, van der Stoep $\mathrm{J}$, Emans D, et al. The PET-boost randomised phase II dose-escalation trial in non-small cell lung cancer. Radiother Oncol 2012;104:67-71. doi: 10.1016/j. radonc.2012.03.005

[59] Mera Iglesias M, Aramburu Núñez D, Del Olmo Claudio JL, López Medina A, Landesa-Vázquez I, Salvador Gómez F, et al. Multimodality functional imaging in radiation therapy planning: relationships between dynamic contrastenhanced MRI, diffusion-weighted MRI, and ${ }^{18}$ F-FDG PET. Comput Math Methods Med 2015;2015:103843.

[60] Cairns RA, Kalliomaki T, Hill RP. Acute (cyclic) hypoxia enhances spontaneous metastasis of KHT murine tumors. Cancer Res 2001;61:8903-8.

[61] Cairns RA, Hill RP. Acute hypoxia enhances spontaneous lymph node metastasis in an orthotopic murine model of human cervical carcinoma. Cancer Res 2004;64:2054-61. doi: 10.1158/0008-5472.CAN-03-3196.

[62] Rofstad EK, Galappathi K, Mathiesen B, Ruud EB. Fluctuating and diffusionlimited hypoxia in hypoxia-induced metastasis. Clin Cancer Res 2007;13:1971-
8. doi: 10.1158/1078-0432.CCR-06-1967.

[63] Wouters BG, Brown JM. Cells at intermediate oxygen levels can be more important than the "hypoxic fraction" in determining tumor response to fractionated radiotherapy. Radiat Res 1997;147:541-50. doi: 10.2307/3579620.

[64] Wang K, Yorke E, Nehmeh SA, Humm JL, Ling CC. Modeling acute and chronic hypoxia using serial images of ${ }^{18}$ F-FMISO PET. Med Phys 2009;36:4400-8. doi: $10.1118 / 1.3213092$.

[65] Dence CS, Ponde DE, Welch MJ, Lewis JS. Autoradiographic and small-animal PET comparisons between ${ }^{18} \mathrm{~F}$-FMISO, ${ }^{18} \mathrm{~F}$-FDG, ${ }^{18} \mathrm{~F}$-FLT and the hypoxic selective ${ }^{64} \mathrm{Cu}-\mathrm{ATSM}$ in a rodent model of cancer. Nucl Med Biol 2008;35:71320. doi: 10.1016/j.nucmedbio.2008.06.001.

[66] Hansen AE, Kristensen AT, Jorgensen JT, McEvoy FJ, Busk M, van der Kogel AJ, et al. ${ }^{64} \mathrm{Cu}-\mathrm{ATSM}$ and ${ }^{18} \mathrm{FDG}$ PET uptake and ${ }^{64} \mathrm{Cu}-\mathrm{ATSM}$ autoradiography in spontaneous canine tumors: comparison with pimonidazole hypoxia immunohistochemistry. Radiat Oncol 2012;7:89. doi: 10.1186/1748-717X-7-89.

[67] Mortensen LS, Johansen J, Kallehauge J, Primdahl H, Busk M, Lassen P, et al. FAZA PET/CT hypoxia imaging in patients with squamous cell carcinoma of the head and neck treated with radiotherapy: results from the DAHANCA 24 trial. Radiother Oncol 2012;105:14-20. doi: 10.1016/j.radonc.2012.09.015.

[68] Sovik A, Malinen E, Bruland OS, Bentzen SM, Olsen DR. Optimization of tumour control probability in hypoxic tumours by radiation dose redistribution: a modelling study. Phys Med Biol 2007;52:499-513. doi: 10.1088/0031$9155 / 52 / 2 / 013$

[69] Hornback NB. Historical aspects of hyperthermia in cancer therapy. Radiol Clin North Am 1989;27:481-8

[70] Nielsen OS, Henle KJ, Overgaard J. Arrhenius analysis of survival curves from thermotolerant and step-down heated L1A2 cells in vitro. Radiat Res 1982;91:468-82. doi: 10.2307/3575886.

[71] Urano M, Kuroda M, Nishimura Y. For the clinical application of thermochemotherapy given at mild temperatures. Int J Hyperthermia 1999;15:79-107. doi: $10.1080 / 026567399285765$.

[72] Okajima K, Griffin RJ, Iwata K, Shakil A, Song CW. Tumor oxygenation af ter mild-temperature hyperthermia in combination with carbogen breathing: dependence on heat dose and tumor type. Radiat Res 1998;149:294-9. doi: $10.2307 / 3579963$

[73] Shakil A, Osborn JL, Song CW. Changes in oxygenation status and blood flow in a rat tumor model by mild temperature hyperthermia. Int J Radiat Oncol Biol Phys 1999;43:859-65. doi: 10.1016/S0360-3016(98)00516-1.

[74] Vujaskovic Z, Poulson JM, Gaskin AA, Thrall DE, Page RL, Charles HC, et al. Temperature-dependent changes in physiologic parameters of spontaneous canine soft tissue sarcomas after combined radiotherapy and hyperthermia treatment. Int J Radiat Oncol Biol Phys 2000;46:179-85. doi: 10.1016/S03603016(99)00362-4

[75] Saga T, Sakahara H, Nakamoto Y, Sato N, Ishimori T, Mamede M, et al. Enhancement of the therapeutic outcome of radio-immunotherapy by combination with whole-body mild hyperthermia. Eur J Cancer 2001;37:1429-34. doi: 10.1016/S0959-8049(01)00138-1.

[76] Sen A, Capitano ML, Spernyak JA, Schueckler JT, Thomas S, Singh AK, et al. Mild elevation of body temperature reduces tumor interstitial fluid pressure and hypoxia and enhances efficacy of radiotherapy in murine tumor models. Cancer Res 2011;71:3872-80. doi: 10.1158/0008-5472.CAN-10-4482.

[77] Falk MH, Issels RD. Hyperthermia in oncology. Int J Hyperthermia 2001;17:118. doi: $10.1080 / 02656730118511$

[78] Jones EL, Samulski TV, Dewhirst MW, Alvarez-Secord A, Berchuck A, ClarkePearson D, et al. A pilot phase II trial of concurrent radiotherapy, chemotherapy, and hyperthermia for locally advanced cervical carcinoma. Cancer 2003;98:277-82. doi: 10.1002/cncr.11475.

[79] Vujaskovic Z, Kim DW, Jones E, Lan L, McCall L, Dewhirst MW, et al. A phase I/II study of neoadjuvant liposomal doxorubicin, paclitaxel, and hyperthermia in locally advanced breast cancer. Int J Hyperthermia 2010;26:514-21. doi: $10.3109 / 02656731003639364$

[80] Lyu X, Zheng D, Zhang H, Zhang T, Han N, Zhang M, et al. Hyperthermia improves immune function and radiotherapy efficacy in patients with postoperative recurrent gastric cancer. Hepatogastroenterology 2014;61:2428-33.

[81] Hunt CR, Pandita RK, Laszlo A, Higashikubo R, Agarwal M, Kitamura T, al. Hyperthermia activates a subset of ataxia-telangiectasia mutated effectors independent of DNA strand breaks and heat shock protein 70 status. Cancer Res 2007;67:3010-7. doi: 10.1158/0008-5472.CAN-06-4328.

[82] Pandita TK, Pandita S, Bhaumik SR. Molecular parameters of hyperthermia for radiosensitization. Crit Rev Eukaryot Gene Expr 2009;19:235-51. doi: 10.1615/CritRevEukarGeneExpr.v19.i3.50.

[83] Man J, Shoemake JD, Ma T, Rizzo AE, Godley AR, Wu Q, et al. Hyperthermia sensitizes glioma stem-like cells to radiation by inhibiting AKT signaling. Cancer Res 2015;75:1760-9. doi: 10.1158/0008-5472.CAN-14-3621.

[84] Datta NR, Puric E, Schneider R, Weber DC, Rogers S, Bodis S. Could hyperthermia with proton therapy mimic carbon ion therapy? Exploring thermo-radiobiological rationale. Int J Hyperthermia 2014;30:524-30. doi: 10.3109/02656736.2014.963703

[85] Adams GE, Flockhart IR, Smithen CE, Stratford IJ, Wardman P, Watts ME. Electron-affinic sensitization. VII. A correlation between structures, one-elec- 
tron reduction potentials, and efficiencies of nitroimidazoles as hypoxic cell radiosensitizers. Radiat Res 1976;67:9-20. doi: 10.2307/3574491.

[86] Oronsky BT, Knox SJ, Scicinski J. Six degrees of separation: the oxygen effect in the development of radiosensitizers. Transl Oncol 2011;4:189-98. doi: $10.1593 /$ tlo. 11166

[87] Brown JM. Selective radiosensitization of the hypoxic cells of mouse tumors with the nitroimidazoles metronidazole and Ro 7-0582. Radiat Res 1975;64:633-47. doi: 10.2307/3574253.

[88] Brown JM, Yu NY. Radiosensitization of hypoxic cells in vivo by SR 2508 at low radiation doses: a preliminary report. Int J Radiat Oncol Biol Phys 1984;10:1207-12. doi: 10.1016/0360-3016(84)90319-5.

[89] Overgaard J, Overgaard M, Nielsen OS, Pedersen AK, Timothy AR. A comparative investigation of nimorazole and misonidazole as hypoxic radiosensitizers in a C3H mammary carcinoma in vivo. Br J Cancer 1982;46:904-11. doi: 10.1038/bjc. 1982.300 .

[90] Timothy AR, Overgaard J, Overgaard M. A phase I clinical study of nimorazole as a hypoxic radiosensitizer. Int J Radiat Oncol Biol Phys 1984;10:1765-8. doi: 10.1016/0360-3016(84)90545-5.

[91] Overgaard J, Hansen HS, Overgaard M, Bastholt L, Berthelsen A, Specht L, et al. A randomized double-blind phase III study of nimorazole as a hypoxic radiosensitizer of primary radiotherapy in supraglottic larynx and pharynx carcinoma. Results of the Danish Head and Neck Cancer Study (DAHANCA) Protocol 5-85. Radiother Oncol 1998;46:135-46. doi: 10.1016/S0167-8140(97)00220-X.

[92] Hassan Metwally MA, Ali R, Kuddu M, Shouman T, Strojan P, Iqbal K, et al. IAEA-HypoX. A randomized multicenter study of the hypoxic radiosensitizer nimorazole concomitant with accelerated radiotherapy in head and neck squamous cell carcinoma. Radiother Oncol 2015;116:15-20. doi: 10.1016/j. radonc.2015.04.005.

[93] Kunert MP, Liard JF, Abraham DJ. RSR-13, an allosteric effector of hemoglobin, increases systemic and iliac vascular resistance in rats. Am J Physiol 1996;271:H602-13.

[94] Kunert MP, Liard JF, Abraham DJ, Lombard JH. Low-affinity hemoglobin increases tissue $\mathrm{PO}_{2}$ and decreases arteriolar diameter and flow in the rat cremaster muscle. Microvasc Res 1996;52:58-68. doi: 10.1006/mvre.1996.0043.

[95] Suh JH, Stea B, Nabid A, Kresl JJ, Fortin A, Mercier JP, et al. Phase III study of efaproxiral as an adjunct to whole-brain radiation therapy for brain metastases. J Clin Oncol 2006;24:106-14. doi: 10.1200/JCO.2004.00.1768.

[96] Olson JJ, Paleologos NA, Gaspar LE, Robinson PD, Morris RE, Ammirati M, et al. The role of emerging and investigational therapies for metastatic brain tumors: a systematic review and evidence-based clinical practice guideline of selected topics. J Neurooncol 2010;96:115-42. doi: 10.1007/s11060-009-00583.

[97] Meng F, Evans JW, Bhupathi D, Banica M, Lan L, Lorente G, et al. Molecular and cellular pharmacology of the hypoxia-activated prodrug TH-302. Mol Cancer Ther 2011;11:740-51.

[98] Weiss GJ, Infante JR, Chiorean EG, Borad MJ, Bendell JC, Molina JR, et al. Phase 1 study of the safety, tolerability, and pharmacokinetics of TH-302, a hypoxia-activated prodrug, in patients with advanced solid malignancies. Clin Cancer Res 2011;17:2997-3004. doi: 10.1158/1078-0432.CCR-10-3425.

[99] Yoon C, Lee HJ, Park DJ, Lee YJ, Tap WD, Eisinger-Mathason TS, et al. Hypoxia-activated chemotherapeutic TH-302 enhances the effects of VEGF-A inhibition and radiation on sarcomas. Br J Cancer 2015;113:46-56. doi: 10.1038/ bjc.2015.186.

[100] Peeters SG, Zegers CM, Biemans R, Lieuwes NG, van Stiphout RG, Yaromina A, et al. TH-302 in combination with radiotherapy enhances the therapeutic outcome and is associated with pretreatment $\left[{ }^{18} \mathrm{~F}\right] \mathrm{HX} 4$ hypoxia PET imaging. Clin Cancer Res 2015;21:2984-92. doi: 10.1158/1078-0432.CCR-15-0018.

[101] Yeung R, McConnell Y, Warkentin H, Graham D, Warkentin B, Joseph K, et al. Intensity-modulated radiotherapy (IMRT) vs helical tomotherapy (HT) in concurrent chemoradiotherapy (CRT) for patients with anal canal carcinoma (ACC): an analysis of dose distribution and toxicities. Radiat Oncol 2015;10:92. doi: 10.1186/s13014-015-0398-4.

[102] Budach V, Stromberger C, Poettgen C, Baumann M, Budach W, Grabenbauer $\mathrm{G}$, et al. Hyperfractionated accelerated radiation therapy (HART) of $70.6 \mathrm{~Gy}$ with concurrent 5-FU/Mitomycin $\mathrm{C}$ is superior to HART of $77.6 \mathrm{~Gy}$ alone in locally advanced head and neck cancer: long-term results of the ARO 95-06 randomized phase III trial. Int J Radiat Oncol Biol Phys 2015;91:916-24. doi: 10.1016/j.ijrobp.2014.12.034.

[103] Zeman EM, Brown JM, Lemmon MJ, Hirst VK, Lee WW. SR-4233: a new bioreductive agent with high selective toxicity for hypoxic mammalian cells. Int J Radiat Oncol Biol Phys 1986;12:1239-42. doi: 10.1016/0360-3016(86)902671.

[104] Brown JM. SR 4233 (tirapazamine): a new anticancer drug exploiting hypoxia in solid tumours. Br J Cancer 1993;67:1163-70. doi: 10.1038/bjc. 1993.220.

[105] DiSilvestro PA, Ali S, Craighead PS, Lucci JA, Lee YC, Cohn DE, et al. Phase III randomized trial of weekly cisplatin and irradiation versus cisplatin and tirapazamine and irradiation in stages IB2, IIA, IIB, IIIB, and IVA cervical carcinoma limited to the pelvis: a Gynecologic Oncology Group study. J Clin Oncol 2014;32:458-64. doi: 10.1200/JCO.2013.51.4265.

[106] Patterson LH, McKeown SR, Ruparelia K, Double JA, Bibby MC, Cole S, et al.
Enhancement of chemotherapy and radiotherapy of murine tumours by AQ4N, a bioreductively activated anti-tumour agent. Br J Cancer 2000;82:1984-90.

[107] Nishida CR, Ortiz de Montellano PR. Reductive heme-dependent activation of the n-oxide prodrug $\mathrm{AQ} 4 \mathrm{~N}$ by nitric oxide synthase. J Med Chem 2008;51:5118-20. doi: 10.1021/jm800496s.

[108] McKeown SR, Hejmadi MV, McIntyre IA, McAleer JJ, Patterson LH. AQ4N: an alkylaminoanthraquinone $\mathrm{N}$-oxide showing bioreductive potential and positive interaction with radiation in vivo. Br J Cancer 1995;72:76-81. doi: 10.1038/bjc.1995.280.

[109] Los M, Roodhart JM, Voest EE. Target practice: lessons from phase III trials with bevacizumab and vatalanib in the treatment of advanced colorectal cancer. Oncologist 2007;12:443-50. doi: 10.1634/theoncologist.12-4-443.

[110] Nagengast WB, de Vries EG, Hospers GA, Mulder NH, de Jong JR, Holle$\mathrm{ma} \mathrm{H}$, et al. In vivo VEGF imaging with radiolabeled bevacizumab in a human ovarian tumor xenograft. J Nucl Med 2007;48:1313-9. doi: 10.2967/ jnumed.107.041301.

[111] Nagengast WB, Hooge MN, van Straten EM, Kruijff S, Brouwers AH, den Dunnen WF, et al. VEGF-SPECT with ${ }^{111}$ In-bevacizumab in stage III/IV melanoma patients. Eur J Cancer 2011;47:1595-602. doi: 10.1016/j.ejca.2011.02.009.

[112] Ashrafi SA, Hosseinimehr SJ, Varmira K, Abedi SM. Radioimmunotherapy with ${ }^{131}$ I-bevacizumab as a specific molecule for cells with overexpression of the vascular endothelial growth factor. Cancer Biother Radiopharm 2012;27:420-5. doi: 10.1089/cbr.2012.1224.

[113] Welsh S, Williams R, Kirkpatrick L, Paine-Murrieta G, Powis G. Antitumor activity and pharmacodynamic properties of PX-478, an inhibitor of hypoxiainducible factor-1alpha. Mol Cancer Ther 2004;3:233-44

[114] Palayoor ST, Mitchell JB, Cerna D, Degraff W, John-Aryankalayil M, Coleman CN. PX-478, an inhibitor of hypoxia-inducible factor-1alpha, enhances radiosensitivity of prostate carcinoma cells. Int J Cancer 2008;123:2430-7. doi 10.1002/ijc. 23807 .

[115] Jacoby JJ, Erez B, Korshunova MV, Williams RR, Furutani K, Takahashi O, et al. Treatment with HIF-1 $\alpha$ antagonist PX-478 inhibits progression and spread of orthotopic human small cell lung cancer and lung adenocarcinoma in mice. J Thorac Oncol 2010;5:940-9. doi: 10.1097/JTO.0b013e3181dc211f.

[116] Koh MY, Spivak-Kroizman T, Venturini S, Welsh S, Williams RR, Kirkpatrick DL, et al. Molecular mechanisms for the activity of PX-478, an antitumo inhibitor of the hypoxia-inducible factor-1alpha. Mol Cancer Ther 2008;7:90100. doi: 10.1158/1535-7163.MCT-07-0463.

[117] Greenberger LM, Horak ID, Filpula D, Sapra P, Westergaard M, Frydenlund HF, et al. A RNA antagonist of hypoxia-inducible factor-1alpha, EZN-2968, inhibits tumor cell growth. Mol Cancer Ther 2008;7:3598-608. doi: 10.1158/1535 7163.MCT-08-0510.

[118] Jeong W, Rapisarda A, Park SR, Kinders RJ, Chen A, Melillo G, et al. Pilot trial of EZN-2968, an antisense oligonucleotide inhibitor of hypoxia-inducible factor-1 alpha (HIF-1 $\alpha$ ), in patients with refractory solid tumors. Cancer Chemother Pharmacol 2013;73:343-8.

[119] Moeller BJ, Cao Y, Li CY, Dewhirst MW. Radiation activates HIF-1 to regulate vascular radiosensitivity in tumors: role of reoxygenation, free radicals, and stress granules. Cancer Cell 2004;5:429-41. doi: 10.1016/S15356108(04)00115-1.

[120] Luo W, Ge W, Song J, Chen C, Xu H, Ming P. Blocking HIF-1 $\alpha$ following radiotherapy to prolong and enhance the immune effects of radiotherapy: a hypothesis. Med Sci Monit 2014;20:2106-8. doi: 10.12659/MSM.891048.

[121] Lee HJ, Yoon C, Park do J, Kim YJ, Schmidt B, Lee YJ, et al. Inhibition of vascular endothelial growth factor A and hypoxia-inducible factor $1 \alpha$ maximizes the effects of radiation in sarcoma mouse models through destruction of tumor vasculature. Int J Radiat Oncol Biol Phys 2015;91:621-30. doi: 10.1016/j. ijrobp.2014.10.047.

[122] Helbig L, Koi L, Brüchner K, Gurtner K, Hess-Stumpp H, Unterschemmann K, et al. Hypoxia-inducible factor pathway inhibition resolves tumor hypoxia and improves local tumor control after single-dose irradiation. Int J Radiat Oncol Biol Phys 2014;88:159-66. doi: 10.1016/j.ijrobp.2013.09.047.

[123] Steffens MG, Boerman OC, Oosterwijk-Wakka JC, Oosterhof GO, Witjes JA, Koenders EB, et al. Targeting of renal cell carcinoma with iodine-131-labeled chimeric monoclonal antibody G250. J Clin Oncol 1997;15:1529-37.

[124] Bleumer I, Knuth A, Oosterwijk E, Hofmann R, Varga Z, Lamers C, et al. A phase II trial of chimeric monoclonal antibody G250 for advanced renal cell carcinoma patients. Br J Cancer 2004;90:985-90. doi: 10.1038/sj.bjc.6601617.

[125] Stillebroer AB, Boerman OC, Desar IM, Boers-Sonderen MJ, van Herpen $\mathrm{CM}$, Langenhuijsen JF, et al. Phase 1 radioimmunotherapy study with lutetium 177-labeled anti-carbonic anhydrase IX monoclonal antibody girentuximab in patients with advanced renal cell carcinoma. Eur Urol 2013;64:478-85. doi: 10.1016/j.eururo.2012.08.024.

[126] Divgi CR, Pandit-Taskar N, Jungbluth AA, Reuter VE, Gönen M, Ruan S, et al. Preoperative characterisation of clear-cell renal carcinoma using iodine124-labelled antibody chimeric G250 $\left({ }^{124} \mathrm{I}-\mathrm{cG} 250\right)$ and PET in patients with renal masses: A phase I trial. Lancet Oncol 2007;8:304-10. doi: 10.1016/S14702045(07)70044-X.

[127] Smaldone MC, Chen DY, Yu JQ, Plimack ER. Potential role of ${ }^{124}$ I-girentuximab in the presurgical diagnosis of clear-cell renal cell cancer. Biologics 
2012;6:395-407.

[128] Pryma DA, O’Donoghue JA, Humm JL, Jungbluth AA, Old LJ, Larson SM, et al. Correlation of in vivo and in vitro measures of carbonic anhydrase IX antigen expression in renal masses using antibody ${ }^{124} \mathrm{I}-\mathrm{cG} 250$. J Nucl Med 2011;52:535-40. doi: 10.2967/jnumed.110.083295.

[129] Garrison JC, Rold TL, Sieckman GL, Naz F, Sublett SV, Figueroa SD, et al. Evaluation of the pharmacokinetic effects of various linking group using the ${ }^{111}$ In-DOTA-X-BBN(7-14)NH2 structural paradigm in a prostate cancer model. Bioconjug Chem 2008;19:1803-12. doi: 10.1021/bc8001375.

[130] Ballard B, Jiang Z, Soll CE, Revskaya E, Cutler CS, Dadachova E, et al. In vitro and in vivo evaluation of melanin-binding decapeptide 4B4 radiolabeled with
${ }^{177} \mathrm{Lu},{ }^{166} \mathrm{Ho}$, and ${ }^{153} \mathrm{Sm}$ radiolanthanides for the purpose of targeted radionuclide therapy of melanoma. Cancer Biother Radiopharm 2011;26:547-56. doi: 10.1089/cbr.2011.0954.

[131] Zhou Z, Wagh NK, Ogbomo SM, Shi W, Jia Y, Brusnahan SK, et al. Synthesis and in vitro and in vivo evaluation of hypoxia-enhanced ${ }^{111}$ In-bombesin conjugates for prostate cancer imaging. J Nucl Med 2013;54:1605-12. doi: 10.2967 jnumed.112.117986.

[132] Reubi JC, Wenger S, Schmuckli-Maurer J, Schaer JC, Gugger M. Bombesin receptor subtypes in human cancers: Detection with the universal radioligand ${ }^{125}$ I-[D-TYR $\left.{ }^{6}, \beta-\mathrm{ALA}^{11}, \mathrm{PHE}^{13}, \mathrm{NLE}^{14}\right]$ bombesin(6-14). Clin Cancer Res 2002;8:1139-46. 